\title{
Оценка оползневых процессов на территории г. Томска с использованием ГИС-технологий
}

\author{
(О2021 А. В. Леонова, Л. А. Строкова ${ }^{\bowtie}$, А. Н. Никитенков \\ ${ }^{1}$ Национальный исследовательский Томский политехнический университет, \\ пр. Ленина 30, 634050, Томск, Российская Федерация
}

\begin{abstract}
Аннотация
Введение: В настоящее время в городе Томске увеличивается площадь застройки, появляются новые микрорайоны на ранее неосвоенных землях (например, на левобережье р. Томь), происходит перепланировка и реконструкция центральной части города. Без учета динамики, механизмов, факторов и закономерностей развития опасных природных и техно-природных процессов, прогноза их развития, невозможно качественное развитие территории. Цель работы - установить закономерности распространения оползней, оценить интенсивность их развития и спрогнозировать вероятность их проявления в пределах новых границ города.
\end{abstract}

Методы исследований: Оценка и прогноз развития оползней выполнялись с использованием ГИСтехнологий, которые являются важным инструментом в процессе управления городом благодаря их возможности обрабатывать и анализировать многомерные данные о геологической среде. Для определения «веса» факторов, обусловливающих развитие оползней, использовались два метода: анализа иерархий (analytical hierarchical process, AHP) и соотношения частотностей (frequency ratio, FR). Для валидации карт восприимчивости использовался анализ кривых рабочей характеристики приемника (Receiver Operating Characteristics, ROC).

Результаты и обсуждение: Составлена карта распространения оползней на территории города, включающаяся 25 полигонов. Затем эти полигоны были случайным образом разбиты на две части: 17 полигонов (70\%) для обучения модели и 8 полигонов (30\%) для валидации модели. Для анализа пространственных закономерностей, обусловливающих развитие оползней, выбрано семь факторов: уклон поверхности, экспозиция склона, кривизна, абсолютные отметки поверхности, геологическое строение территории; типы фильтрационных разрезов, расстояние до реки. Используя обучающий набор данных, были построены прогнозные карты восприимчивости на основе проведенного ранжирования факторов двумя методами. Пространственная корреляция между местоположением оползней и обусловливающими их факторами была выявлена с помощью статистических моделей, на основе ГИС. Качество моделей оценивалось с помощью анализа ROC-кривых. Площадь под кривой (составила 0.750 для AHP-модели и 0.844 для FR-модели, что говорит о высоком качестве прогнозных карт. Итак, оба методы оказались пригодными в оценке восприимчивости территории к оползням.

Bblвoдbl: Впервые построены карты восприимчивости территории к оползням в новых границах города, проверено качество моделей. Построенные карты рекомендуется использовать для контроля и оперативного управления состоянием геологической среды, при оценке стоимости земель городской территории, в учебной работе при преподавании дисциплины «Инженерная геодинамика».

Ключевые слова: оползни, восприимчивость, картографирование, метод соотношения частотностей, метод анализа иерархий, анализ ROC-кривых

Контент доступен под лицензией Creative Commons Attribution 4.0 License.

\footnotetext{
Строкова Людмила Александровна, e-mail: sla@tpu.ru
} 
Для цчитирования: Леонова А. В., Строкова Л. А., Никитенков А. Н. Оценка оползневых процессов на территории г. Томска с использованием ГИС-технологий // Вестник Воронежского государственного университета. Серия: Геология. 2021. №1. С. 94-103. DOI: https://doi.org/10.17308/geology.2021.1/3341

\section{Введение}

На территории г. Томска развиты различные экзогенные геологические процессы (ЭГП). Причины и факторы, влияющие на их развитие; условия и закономерности изучались М. И. Кучиным, Л. А. Рождественской, Т. Я. Емельяновой, Н. В. Крепша, В.Е. Ольховатенко и др. [1-4]. Оползни имеют широкое развитие на территории г. Томска. Они развиты по склонам рр. Томи и Ушайки.

Лагерный сад является наиболее характерным районом проявления данного процесса. Оползневой участок протяженностью 1.5 км вдоль р. Томь включает 12 эрозионно-оползневых цирков. Здесь выделяют три типа оползней: вязкопластичного течения, скольжения и выпирания. Большое влияние на скорость развития оползневых процессов оказывает высота и крутизна склонов, состав и условия залегания отложений, их обводненность, слабая водоотдача мелких и пылеватых песков и супесей [5]. Активностей оползней после проведения защитных мероприятий в 90-х годах прошлого века низкая. Активность отмечается только на 4 оползневых телах (№№ $1,15 \mathrm{a}$, $16,16 \mathrm{a}$, рис. 1). Величина смещений составляет от 30 до 550 мм в год [6]. Развитие оползней на склоне Лагерного сада оказывают влияние не только природные, но и техногенные факторы, такие как подрезка, пригрузка поверхности склона сооружениями в результате строительства и увеличение обводненности пород [5].

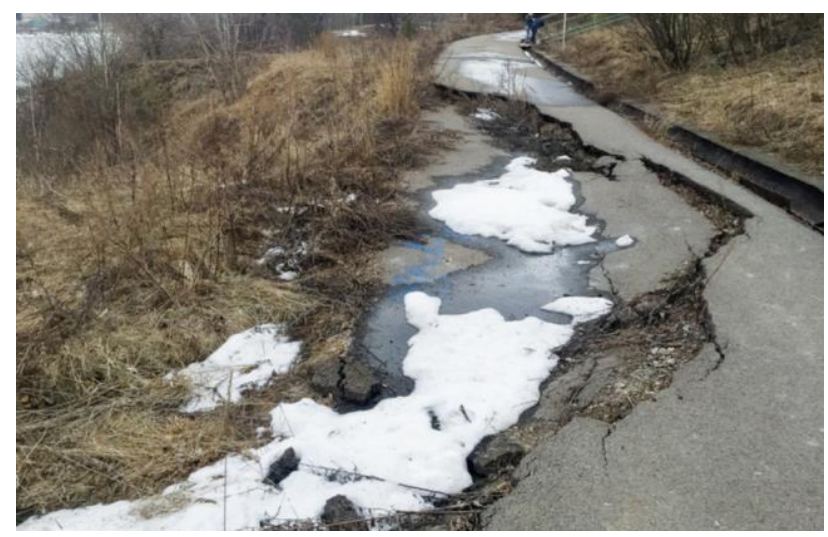

Рис. 1. Оползневой цирк в Лагерном саду [6].

[Fig.1. Landslide in Lagernyi Garden.]

В августе 2020 г. Леоновой А. В. проведено маршрутное обследование склона Лагерного сада с целью установления состояния склона в настоящее время. На асфальтовых дорожках склона обнаружены трещины и деформации дорожек, водосборные лотки забиты мусором и выполнять свою функцию по сбору и отводу поверхностных вод в полной мере не могут, свежих трещин или стенок отрыва на склонах не обнаружено, что может свидетельствовать о приостановке развития оползневых процессов на склоне.

В микрорайоне «Солнечный» оползни представлены двумя типами: вязкопластического течения и скольжения. Причиной развития оползневых процессов в данном случае явились: наличие в разрезе неустойчивых грунтов, пригрузка склона за счет строительства многоэтажных домов и техногенное обводнение грунтового массива, так за период с 1986 по 1993 гг. уровень воды поднялся на 9 м [1]. Этот подъем уровня объясняет увеличившуюся влажность грунтов, ухудшение грунтовых условий и уменьшение несущей способности грунтов. В результате развития оползней в основании дома №89 по улице Иркутский тракт появились трещины в фундаменте, оползень разрушил гаражные постройки, что вызвало расселение двух подъездов в 1996 г. Для дома №89 было установлена подпорная стенка в 2008 г., однако полностью стабилизировать оползень не удалось.

В августе 2020 г. А. В. Леоновой проведено маршрутное обследование склона в микрорайоне «Солнечный» с целью установления его состояния в настоящее время. В ходе обследования были встречены небольшие стенки отрыва на склоне, промоины (рис. 2), свидетельствующие об активности небольших оползней на склоне. Величина смещений составляет 10-23 мм в год [6].

На развитие оползней оказали влияние следующие факторы: геологический (переслаивание в разрезе рыхлых облессованных отложений); геоморфологический (достаточно большая крутизна склона: от 10 до $30^{\circ}$ ), техногенный (нарушение почвенного покрова, в результате чего склон стал менее устойчив к размыву ручьями, техногенное подтопление, что ухудшило свойства грунтов, а также дополнительная загрузка склона жилыми домами).

Картографирование геологических опасностей г. Томска выполнялось разными авторами в 1955, 1990, 2005 гг. [1]. Картографические работы выполнены вручную, карты отрисованы с многочисленными погрешностями по привязке скважин. В связи с изменением границ города, актуальным является построение новых карт с использованием современных ГИС-технологий, позволяющих выполнить оценку, обработку инженерно-геологической информации на более качественном уровне.

Целью данной работы стало установление закономерностей распространения оползней, оценить интенсивность их развития и спрогнозировать вероятность их проявления в пределах новых границ города.

\section{Методика выполнения работ}

Анализ способов картографирования геологических опасностей показал, что наиболее востребованной в методическом плане в настоящее время является технология построения карт восприимчивости (предрасположенности) территории к развитию экзогенных геологических процессов. За последние пять лет опуб- 
a
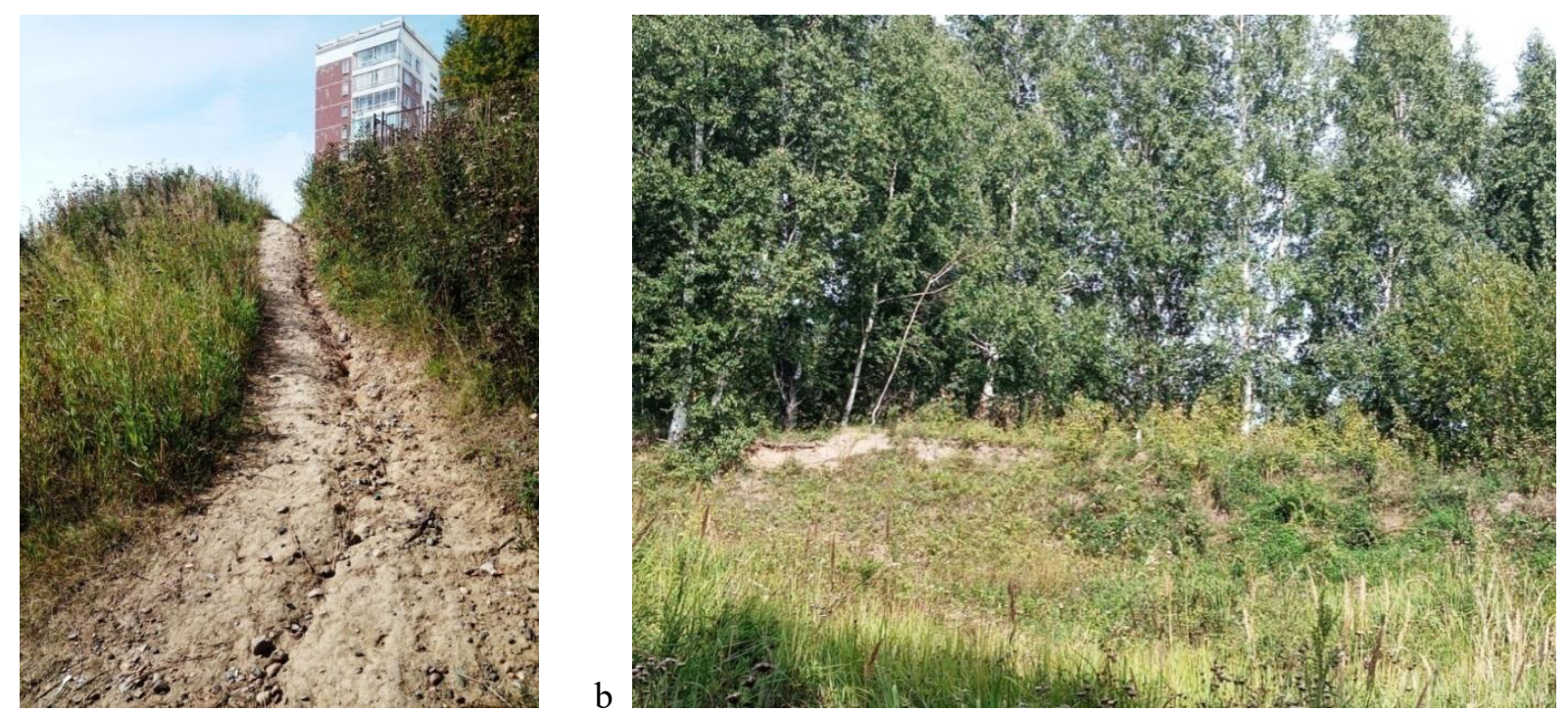

Рис. 2. Оползневой склон в мкр. Солнечный: $a$ - промоина на склоне, $b$ - оползневой цирк.

[Fig. 2. Landslide in the microdistrict Solnechnyi: $a$-washout, $b$-scar.]

ликовано более 5400 работ, посвященных разработке карт районирования подверженности оползням (landslide susceptibility ${ }^{l}$ zoning map) различных районов мира, и более 940 работ - использованию разработанной методики для составления карт районирования подверженности другим геологическим процессам, таким как эрозии, суффозии и т.д. [7-14].

Технология составления подобных карт заключается в следующей последовательности. Вначале выполняется подготовка тематических слоев, таких как: карта проявления ЭГП (инвентаризационная карта); количества выпадающих осадков; литологии; геоморфологии; гидрогеологии; цифровой модели рельефа, с которой можно установить абсолютные отметки рельефа, угол склона, экспозиции и других факторов, обуславливающих возникновение ЭГП и интенсивности их развития. Поскольку значимость каждого фактора в общей оценке разная, в зависимости от региональных геологических, морфометрических, климатических, техногенных условий, необходимо выполнять оценку веса каждого фактора. Такая оценка выполняется с помощью различных статистических и детерминированных подходов, в последние годы, и с использованием теории нечетких множеств. В данной работе для определения весов каждого фактора использовались два метода: анализа иерархий (analytical hierarchical process, AHP) и соотношения частотностей (frequency ratio, FR). Далее тематические карты умножаются на соответствующие веса каждого фактора и объединяются в одну средствами наложения, чтобы получить единую карту восприимчивости к ЭГП. Эта карта подвергается классификации на классы (низкой, средней, высокой степени) восприимчивости в светофорной раскраске. Обычно выделяется от 3 до 5 классов восприимчивости исследуемой области. Для проверки качества моделей предложены разные статистические методы. Наиболее распространены проверки ROC-кривых, относительного индекса плотности оползней и др.

\section{Результаты \\ I. Подготовка информационных слоев}

При составлении карты восприимчивости первым шагом стало определение факторов, определяющих развитие оползней. По опыту подобных исследований в мире, изложенных более чем в 45 публикациях, выбраны следующие факторы: уклон склона; экспозиция; абсолютные отметки поверхности; кривизна склона; расстояние до рек; стратиграфо-генетические комплексы и литология; фильтрационные разрезы; места развития геологических процессов. Каждый фактор включал определенное количество классов (рис. 3). Всего было выбрано 7 факторов (слоев), внутри которых выделено 38 классов.

Следующим шагом после выбора факторов была подготовка тематических карт. Исходными данными для картографических построений послужили: цифровая модель рельефа (ЦМР) - два смежных снимка SRTM (Shuttle Radar Topography Mission) для г. Томска, загруженные с сайта USGS Earthexplorer, и производные из нее карты: уклонов, экспозиция склонов; кривизна и абсолютные отметки, построенные с помощью «ArcGIS Desktop»; картосхема зонирования инженерно-геологических условий, составленная В. Е. Ольховатенко [1]; картосхема типов фильтрационных разрезов [15]; геологическая карта города 1:25000.

\footnotetext{
${ }^{1}$ Susceptibility - восприимчивость, чувствительность, подверженность, предрасположенность, склонность, уязвимость
} 


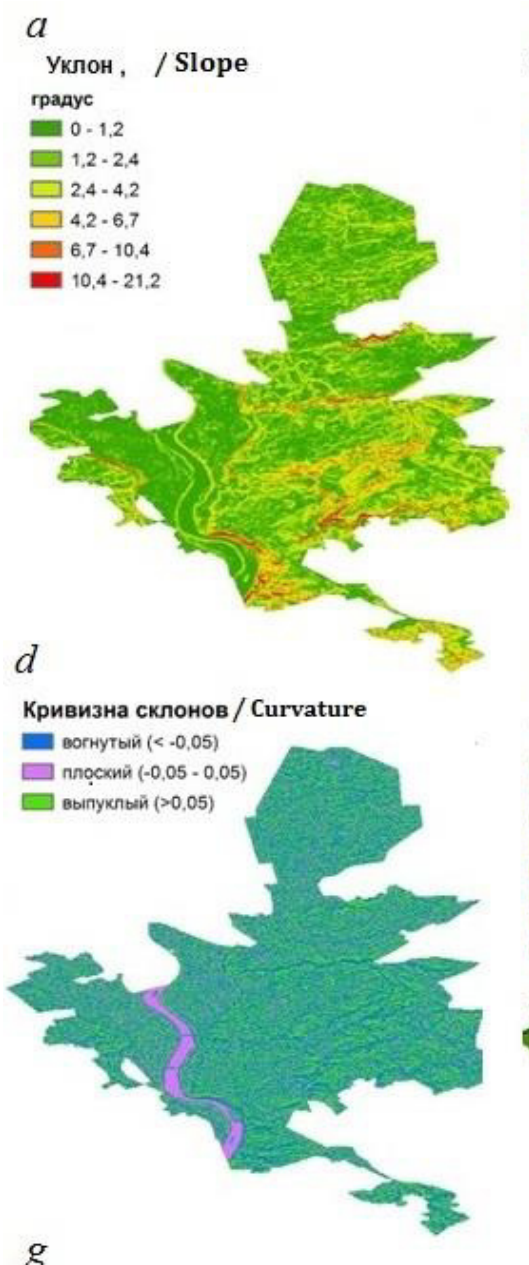

$g$

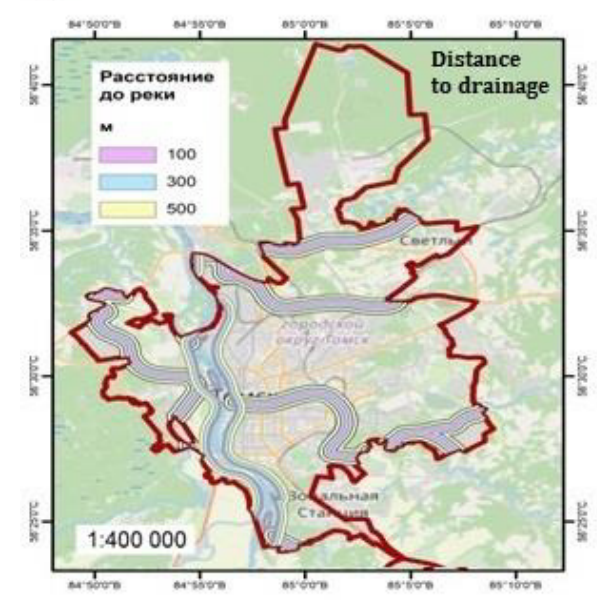

$b$

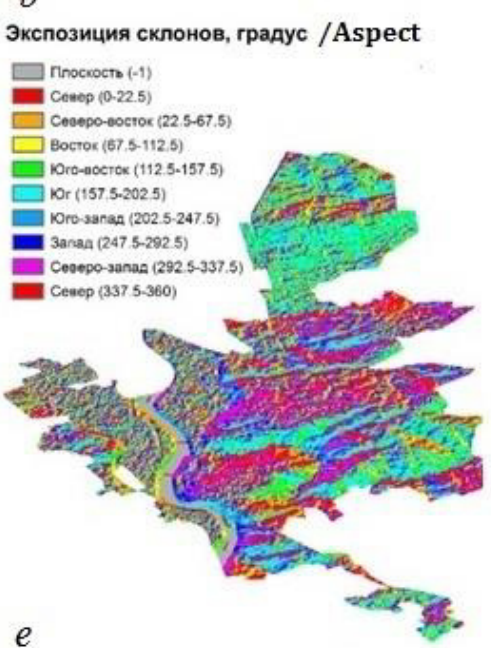

Абсолютные отметки / Elevation, $\mathrm{m}$ M

M. 62.80

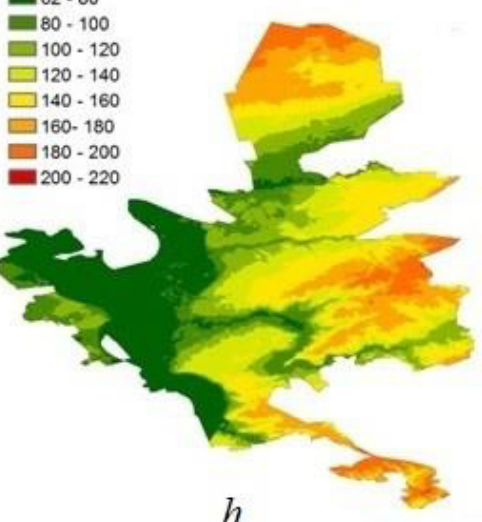

$c$

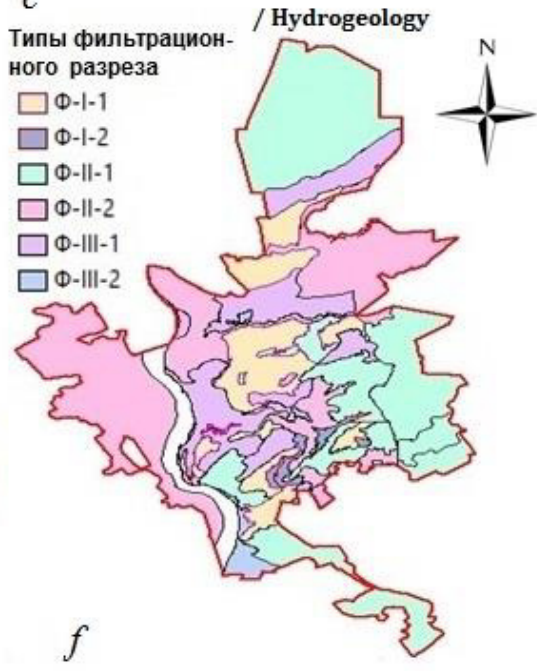

Комплексы пород / Geology

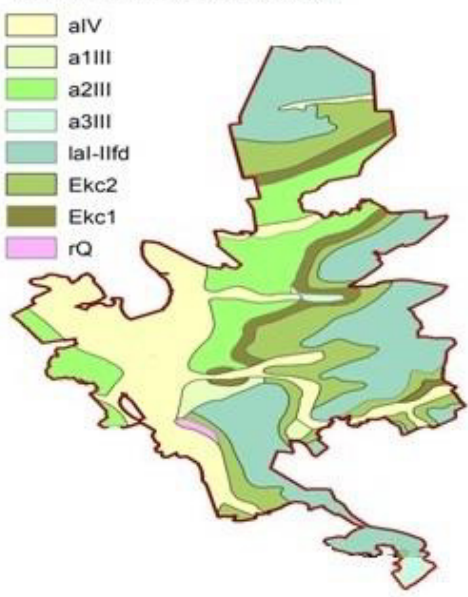

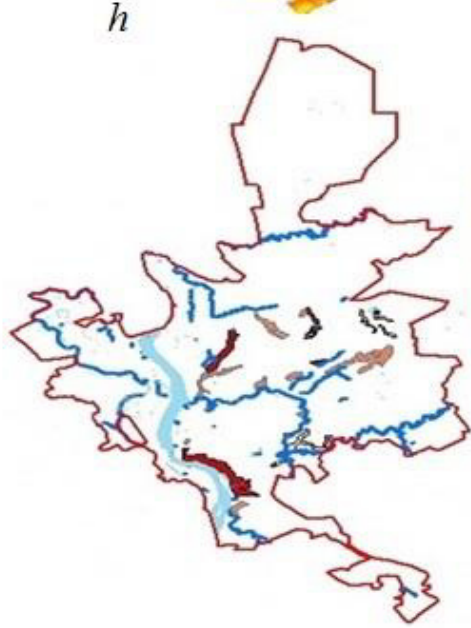

Landslide inventory

Местоположение оползней

Опасные участки

Умеренно опасные участки

Потенциально опасные участки

$1: 400000$

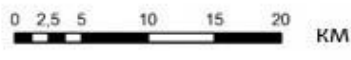

Рис. 3. Исходные слои для карты восприимчивости.

[Fig. 3. Data layers for landslide susceptibility.]

\section{Описание факторов и их классов}

Уклон склона является основным параметром при оценке оползневой опасности. Градиент уклона контролирует скорость подземного стока после выпадения атмосферных осадков, скорость поверхностного стока и содержание влаги в грунтах. По мере увеличения уклона напряжение сдвига в рыхлом почвенном покрове обычно также увеличивается. Исходный файл растрового формата был получен непосредственно из матрицы высот с помощью метода Хорна. Значения уклонов были разделены на следующие классs: <6; 6$12 ;>12$ градусов (рис. $3 a$ ).

Экспозиция склона (рис. 3б). Этот фактор многие авторы также считают важным при составлении карт восприимчивости территории к развитию оползней [7]. Здесь учитываются такие параметры, как воздействие солнечного света, осушающие ветры, осадки (степень насыщения) и неоднородности растительного покрова. 
Всё это может влиять на активизацию развития оползней [8]. По экспозиции территория города разделена на 9 категорий: плоский $\left(-1^{\circ}\right)$; север $\left(0-22.5^{\circ} ; 337.5-360^{\circ}\right)$; северо-восток $\left(22.5-67.5^{\circ}\right)$; восток $\left(67.5-112.5^{\circ}\right)$; юговосток $\left(112.5-157.5^{\circ}\right)$; юг $\left(157.5-202.5^{\circ}\right)$; юго-запад $\left(202.5-247.5^{\circ}\right)$; запад $\left(247.5-292.5^{\circ}\right)$ и северо-запад $\left(292.5-337.5^{\circ}\right)$.

Абсолютные отметки поверхности (рис. 3d). Влияние абсолютных отметок на развитие оползней часто отображается как косвенная зависимость от других факторов. Тематическая карта высот была разделена на 4 класса с разными диапазонами: а) $<100$ м; б) 100 $150 \mathrm{M}$; в) $150-200 \mathrm{м}$; г) > $200 \mathrm{M}$.

Кривизна склона (рис. 32). Значения кривизны характеризует морфологию откосов. Кривизна была выбрана в качестве причинного фактора на том основании, что она влияет на гидрологическое состояние почвенного покрова. Потенциально после выпадения осадков почвенный покров на вогнутом склоне может содержать больше воды и удерживать ее дольше, чем на выпуклом склоне. С другой стороны, часто на выпуклых склонах отмечаются выходы скальных пород. В растре положительные значения кривизны указывают, что поверхность в этих ячейках является выпуклой. Напротив, отрицательные значения указывают на то, что поверхность в этих ячейках вогнута. Нулевое значение указывает, что поверхность плоская. Чем отрицательнее значение, тем выше вероятность возникновения оползней, а чем положительнее значение, тем ниже вероятность.

Расстояние до рек (рис. Зж). Реки могут отрицательно влиять на стабильность, размывая склоны или насыщая нижнюю часть при повышении уровня воды [9]. Также важна взаимосвязь между поверхностными и грунтовыми водами.

Стратиграфо-генетические комплексы и состав пород (литология) - один из наиболее важных параметров при изучении опасных геологических процессов, поскольку разные литологические единицы имеют разную степень предрасположенности территории к ЭГП [10]. Слой оцифрован по геологической карте города 1:25000 (рис. 3e).

Фильтрациионые разрезы (ФР). Кузевановым К. И. [15] построена карта типов фильтрационных разрезов по строению верхней 15-м грунтовой толщи. Водопроницаемые слои при избытке дополнительного питания склонны к развитию процессов подтопления. Их разгрузка в эрозионных уступах способна спровоцировать развитие суффозии и оврагообразования. Утяжеление пород на склоне за счет замачивания может активизировать оползневые процессы (рис. 3в).

Карта распространения оползней (рис. 3з). Для этого была использована карта оползневых зон г. Томска, составленная специалистами ООО «Томскгеомониторинг». Привязка карты была произведена по рекам Томи, Ушайки, Большой и Малой Киргизки. Оползни вынесены с помощью инструмента «полигон».

На карте, взятой за основу, выделены три типа территорий по опасности оползнеобразования: опасные участки (территории, где объем оползневых тел за один раз составляет более 1 тысячи кубов); умеренно опасные участки (где есть условия и уже проявляются проявления оползневых процессов - за 1 раз 1 кубометр); и потенциально опасные участки (пока оползневых процессов нет, но есть реальные условия для их проявления и развития - крутизна склонов, рыхлые отложения, подземные воды). На созданном нами слое, в соответствии с этим делением, оползнеопасные зоны выделены разными оттенками красного цвета, а в таблице атрибутов полигонам присвоены числовые значения от 1 - потенциально опасный участок до 3 - опасный участок. Всего слой включает 25 полигонов оползней. Далее эти полигоны были случайным образом разбиты на две выборки: 16 полигонов (70\%) для обучения модели и 7 полигонов (30\%) для валидации модели. Используя обучающий набор данных, были построены прогнозные карты восприимчивости, прогностическая способность карт оценивалась по проверочному набору данных. Пространственная корреляция между местами оползней и обусловливающими их факторами была выявлена с помощью статистических моделей, на основе ГИС, после определения веса каждого класса каждого фактора.

\section{II. Определение веса факторов}

Выяснение веса каждого фактора и его классов реализовано с использованием двух методов, чтобы добиться объективности при назначении весов, метода анализа иерархий (analytical hierarchical process, AHP) и соотношения частотностей (frequency ratio, FR). Последний метод позволяет оценить реальную площадную пораженность территории ЭГП с помощью ГИС технологий [16].

\section{Метод соотношения частотностей (frequency ratio, FR)}

Для определения «веса» каждого фактора методом FR на первом этапе были посчитаны площади каждого класса каждого фактора и их доли (\%) от площади города. Далее в пределах каждого класса определены площадь проявления ЭГП (в км ${ }^{2}$ и \%), а также отношение \% площади проявления ЭГП к \% площади самого класса (вес FR). Вес каждого фактора и их классов приведены в таблице.

\section{Метод анализа иерархий} (analytical hierarchical process, $A H P$ )

Изучение значимости факторов, обусловливающих формирование и развитие оползней, проводилось также методом анализа иерархий, предложенным Т. Л. Саати в 1970 г. Предложенная им шкала соотношений позволяет оценить важность одного фактора относительно другого фактора. В программе Excel была подготовлена таблица для создания матрицы попарного сравнения факторов развития ЭГП. В процессе сравнения необходимо было определить, во сколько раз альтернатива 1 оказывает большее влияние на развитие процесса, чем альтернатива 2. Например, насколько геологическое 
строение склона важнее его экспозиции и т.д. При сравнении пары факторов, остальные в этот момент в учет не принимаются. После проведения попарного сравнения необходимо проверить транзитивность матрицы (рассчитать индекс согласованности, значение которого не должно превышать 10\%). Проведенное сравнение влияния факторов показало, что наибольшее значение или «вес» имеет стратиграфо-генетический комплекс (СГК) пород, далее - тип фильтрационных разрезов (ФР), крутизна склонов, расстояние до рек. Остальные факторы имеют меньший «вес». Аналогично попарное сравнение было проведено внутри каждого фактора по классам. Веса каждого класса каждого фактора методом АНР представлены в таблице.

Табл. Результаты определения «веса» факторов развития оползней

[Table. Results of the weighting of the landslide-conditioning factors]

\begin{tabular}{|c|c|c|c|c|c|c|}
\hline $\begin{array}{c}\text { Слои данных } \\
\text { [Data layers] }\end{array}$ & $\begin{array}{c}\text { Классы } \\
\text { [Classes] }\end{array}$ & $\begin{array}{c}\% \text { класса } \\
{[\% \text { of total }} \\
\text { area }(\mathrm{a})]\end{array}$ & $\begin{array}{c}\% \text { оползней } \\
{\left[\begin{array}{c}\% \text { of landslide } \\
\text { area }(b)]\end{array}\right.} \\
\end{array}$ & \begin{tabular}{|c|} 
Bec по FR \\
(b/a) \\
FR- weights \\
\end{tabular} & \multicolumn{2}{|c|}{$\begin{array}{l}\text { Bec по AHP } \\
\text { AHP-weights }\end{array}$} \\
\hline \multirow{10}{*}{$\begin{array}{l}\text { Экспозиция } \\
\text { склона, } \\
\text { Aspect }\end{array}$} & Плоские (-1) Flat & 8.2 & 0.62 & 0.08 & 0.01 & \multirow{10}{*}{0.054} \\
\hline & Северные (0-22.5) North & 13.9 & 3.58 & 0.26 & 0.03 & \\
\hline & Северо-восточные (22.5-67.5) North-east & 7.7 & 4.06 & 0.53 & 0.05 & \\
\hline & Восточные (67.5-112.5) East & 10.9 & 2.82 & 0.26 & 0.03 & \\
\hline & Юго-восточные (112.5-157.5) South-east & 20.9 & 8.26 & 0.39 & 0.034 & \\
\hline & Южные (157.5-202.5) South & 11.3 & 24.81 & 2.19 & 0.08 & \\
\hline & Юго-западные (202.5-247.5) South-west & 6.0 & 16.18 & 2.69 & 0.17 & \\
\hline & Западные (247.5-292.5) West & 9.2 & 11.19 & 1.21 & 0.06 & \\
\hline & Северо-западные (292.5-337.5) North-west & 9.1 & 20.80 & 2.28 & 0.12 & \\
\hline & Северные(337.5-360) North & 2.8 & 7.68 & 2.74 & 0.45 & \\
\hline \multirow{3}{*}{$\begin{array}{l}\text { Кривизна } \\
\text { склона } \\
\text { Curvature }\end{array}$} & Вогнутые $(<-0.05)$ Concave & 44.9 & 47.7 & 1.1 & 0.23 & \multirow{3}{*}{0.003} \\
\hline & Плоские (-0.05-0.05) Flat & 9.4 & 3.9 & 0.4 & 0.12 & \\
\hline & Выпуклые (>0.005) Convex & 45.7 & 48.4 & 1.1 & 0.65 & \\
\hline \multirow{4}{*}{$\begin{array}{l}\text { Абсолютные } \\
\text { отметки, м } \\
\text { Elevation }\end{array}$} & $<100$ & 32.5 & 22.4 & 0.68 & 0.13 & \multirow{4}{*}{0.054} \\
\hline & $100-150$ & 38.2 & 56.4 & 1.47 & 0.66 & \\
\hline & $150-200$ & 29.2 & 21.2 & 0.73 & 0.19 & \\
\hline & $>200$ & 0.1 & 0 & 0 & 0.10 & \\
\hline \multirow{3}{*}{$\begin{array}{l}\text { Крутизна } \\
\text { склона, град. } \\
\text { Slope angle }\end{array}$} & $<6$ & 95.6 & 62.34 & 0.7 & 0.06 & \multirow{3}{*}{0.064} \\
\hline & $6-12$ & 4.0 & 30.39 & 7.6 & 0.19 & \\
\hline & $>12$ & 0.4 & 4.64 & 11.6 & 0.74 & \\
\hline \multirow{4}{*}{$\begin{array}{l}\text { Расстояние от } \\
\text { рек, м } \\
\text { /Distance from } \\
\text { Rivers }\end{array}$} & $<100$ & 1.46 & 33.42 & 22.94 & 0.63 & \multirow{4}{*}{0.016} \\
\hline & $100-300$ & 2.77 & 28.46 & 10.29 & 0.24 & \\
\hline & $300-500$ & 2.69 & 37.81 & 14.07 & 0.14 & \\
\hline & $>500$ & 93.09 & 0.30 & 0 & 0 & \\
\hline \multirow{8}{*}{$\begin{array}{l}\text { Стратиграфо- } \\
\text { генетические } \\
\text { комплексы / } \\
\text { Geology }\end{array}$} & $\mathrm{a}^{1} \mathrm{III}$ & 1.85 & 1.87 & 1.01 & 0.09 & \multirow{8}{*}{0.064} \\
\hline & $\mathrm{a}^{2} \mathrm{III}$ & 16.09 & 18.98 & 1.18 & 0.06 & \\
\hline & $a^{3}$ III & 0.35 & 1.33 & 3.80 & 0.19 & \\
\hline & a IV & 25.46 & 15.69 & 0.62 & 0.05 & \\
\hline & laI-IIfd & 32.30 & 25.13 & 0.78 & 0.02 & \\
\hline & $\mathrm{Ekc}_{1}$ & 5.71 & 4.80 & 0.84 & 0.03 & \\
\hline & $\mathrm{Ekc}_{2}$ & 17.86 & 28.66 & 1.60 & 0.13 & \\
\hline & $\mathrm{rQ}$ & 0.38 & 3.54 & 9.32 & 0.43 & \\
\hline \multirow{6}{*}{$\begin{array}{l}\text { Тип фильтра- } \\
\text { ционного } \\
\text { разреза } \\
\text { /Hygrogeology }\end{array}$} & F-I-1 & 13 & 27 & 2.08 & 0.28 & \multirow{6}{*}{0.069} \\
\hline & F-I-2 & 1 & 2 & 2 & 0.04 & \\
\hline & F-II-1 & 38 & 43 & 1.13 & 0.24 & \\
\hline & F-II-2 & 31 & 7 & 0.23 & 0.08 & \\
\hline & F-III-1 & 15 & 13 & 0.87 & 0.21 & \\
\hline & F-III-2 & 2 & 8 & 4 & 0.12 & \\
\hline
\end{tabular}

\section{III.Построение и анализ карт восприимчивости}

Растровые тематические карты с присвоенными значениями для их классов были умножены на соответствующие веса и суммированы, чтобы получить простую карту, где каждая ячейка имеет определенное значение суммарного индекса восприимчивости к оврагам (рис. 4) и проведено классифицирование растра методом «Естественные границы» на 5 категорий: очень, низкая, низкая, средняя, высокая и очень высокая.
Для сравнения двух методов были определены площади зон с разной степенью восприимчивости (рис. 5). Так площади территории с очень низкой и низкой степенью восприимчивости к оползням занимают 42-53\% от площади города, со средней 28-43\%, высокой от 1$10 \%$ и очень высокой степенью 9-14\%. Карты восприимчивости по AHP и FR дали хорошую сходимость по участкам с низкой, средней и очень высокой восприимчивостью. 


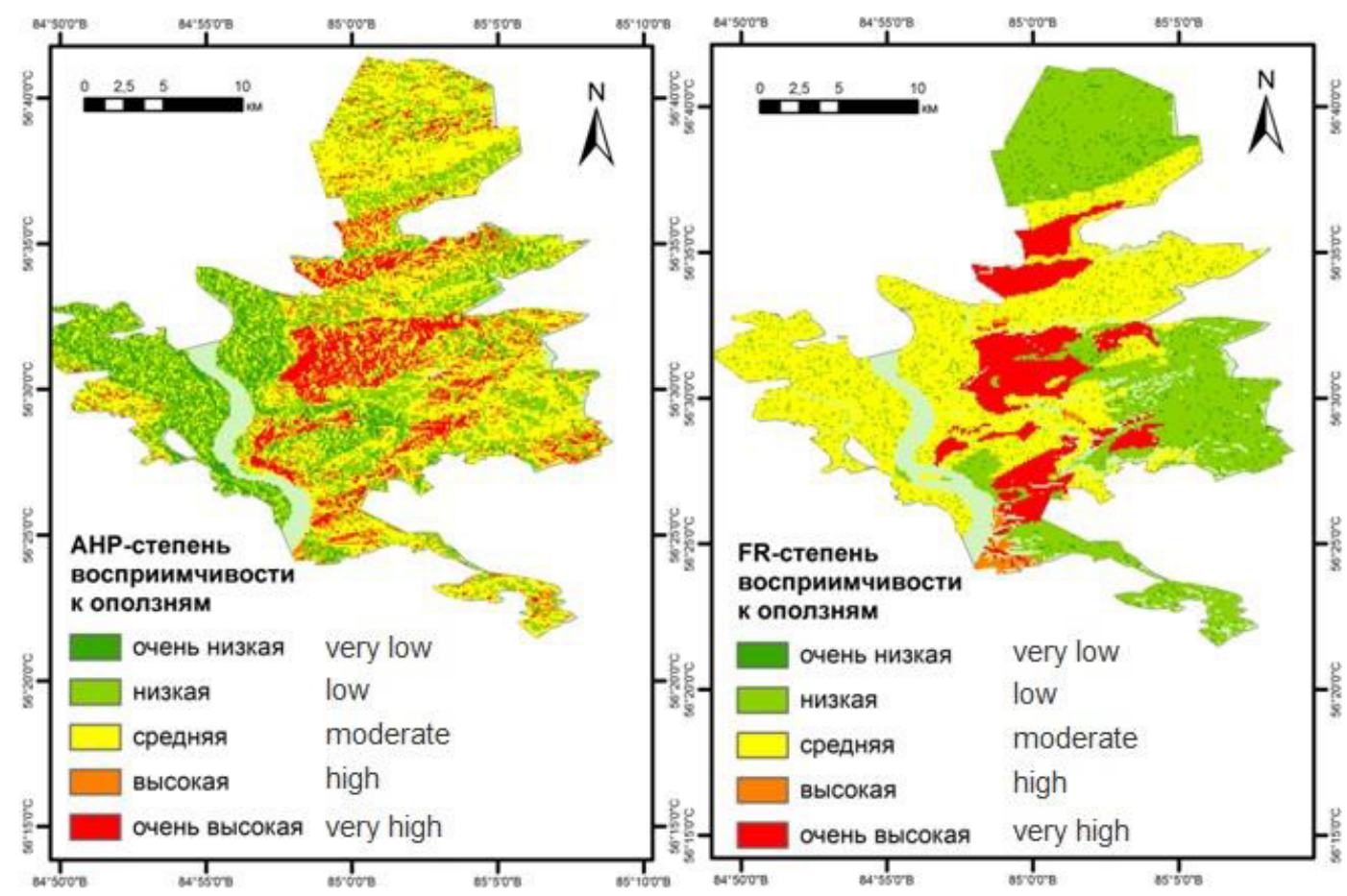

Рис. 4. Карты восприимчивости территории к оползням с использованием AHP (a) и FR методов (b)

[Fig. 4. Landslide susceptibility map of the study area using the AHP model (a) and FR model (b).]

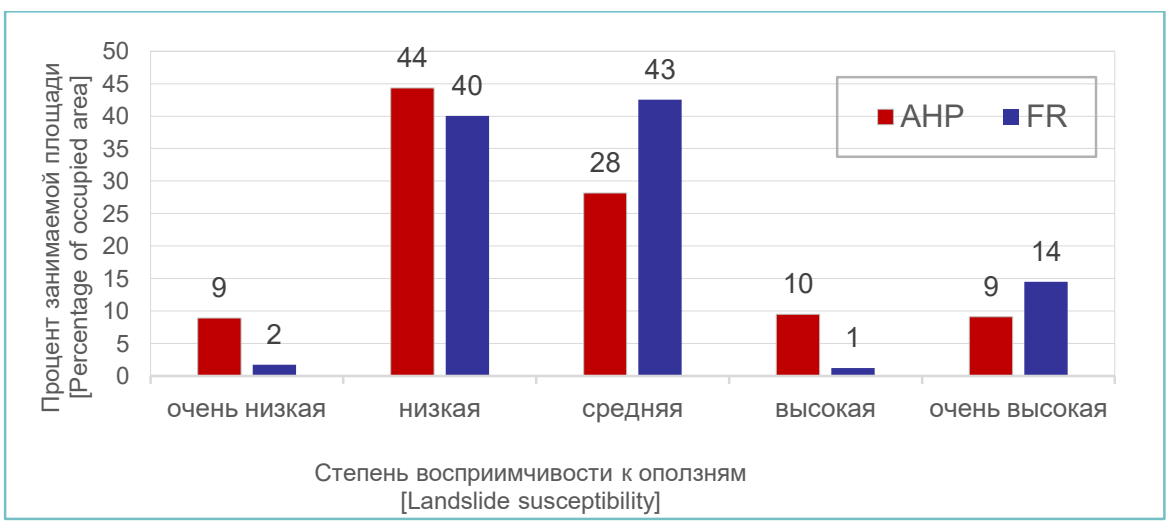

Pис. 5. Сравнение классов по степени восприимчивости, определенных методами AHP и FR.

[Fig. 5. Comparison of landslide susceptibility classes on landslide susceptibility map using the AHP and FR methods.]

\section{IV. Валидация карт}

Для валидации построенных карт восприимчивости к развитию оползней, основанных на разных методах нахождения весов, предложено использовать анализ ROC-кривых, предложенный A. Linden в 2006 г. ROCкривая позволяет определить точность метода, показывая число «правильных» срабатываний [18]. Количественную интерпретацию ROC дает показатель $A U C$ (area under ROC curve) - площадь, ограниченная ROCкривой и осью доли ложных положительных классификаций. Чем выше показатель AUC, тем качественнее классификатор, при этом значение 0.5 демонстрирует непригодность выбранного метода классификации (соответствует случайному гаданию). Для анализа ROCкривых использовался статистический пакет SPSS Statistics. Значения AUC, полученные для оползней ме- тодами AHP и FR, составляют 0.750 и 0.844 соответственно, что говорит о высоком качестве прогнозных карт. Прогностическая способность карт по AHP и FR, определенная по проверочному набору из 8 полигонов, составила 0.800 и 0.833 соответственно.

\section{Выводы}

1. Территория г. Томска характеризуется сложными инженерно-геологическими условиями, что является фактором, благоприятствующим развитию опасных геологических процессов и явлений, таких как оползни, овраги, суффозия, подтопление, заболачивание, просадка, и другие. Эти процессы осложняют хозяйственное освоение территории и снижают эксплуатационную надежность зданий и сооружений. Составлена карта распространения оползней на террито- 
рии города, включающаяся 25 полигонов. Затем эти полигоны были случайным образом разбиты на две части: 17 полигонов (70\%) для обучения модели и 8 полигонов (30\%) для валидации модели.

2. Для анализа пространственных закономерностей, обусловливающих развитие оползней, выбрано семь факторов: уклон поверхности, экспозиция склона, кривизна, абсолютные отметки поверхности, геологическое строение территории; типы фильтрационных разрезов, расстояние до реки.

3. Проведено ранжирование факторов, способствующих активному развитию оползней. Значимость факторов оценена двумя методами: методом анализа иерархий и соотношения частотностей. Последний метод позволил оценить площадную пораженность территории оползнями.

4. Используя обучающий набор данных, были построены прогнозные карты восприимчивости на основе проведенного ранжирования факторов двумя методами. Пространственная корреляция между местами оползней и обусловливающими их факторами была выявлена с помощью статистических моделей, на основе ГИС.

5. Качество моделей оценивалось с помощью анализа ROC-кривых. Площадь под кривой (area under the curve - AUC) составила 0.750 для AНР-модели и 0.844 для FR-модели, что говорит о высоком качестве прогнозных карт. Итак, оба метода оказались пригодными в оценке восприимчивости (предрасположенности) территории к оползням.

6. Построенные карты рекомендуется использовать для контроля и оперативного управления состоянием геологической среды, при оценке стоимости земель городской территории, в учебной работе при преподавании дисциплины «Инженерная геодинамика».

Конфликт интересов: Авторы декларируют отсутствие явных и потенциальных конфликтов интересов, связанных с публикацией настоящей статьи.

\section{ЛИТЕРАТУРА}

1. Ольховатенко В. Е., Рутман М. Г., Лазарев В. М. Опасные природные и техноприродные процессы на территории г. Томска и их влияние на устойчивость природно-технических систем. Томск: Печатная мануфактура, 2005. 152 с.

2. Ольховатенко В. Е., Лазарев В. М., Филимонова И. С. Геоэкологические проблемы застройки территории г. Томска и мероприятия по ее инженерной защите // Вестник Томского государственного архитектурно-строительного университета. 2012. № 1. C. 141-150.

3. Leonova A. V., Lomakina K. M., Dmitrieva S. A., Baranova A. V. Geotechnical properties of gullying in Tomsk oblast. // IOP Conference Series: Earth and Environmental Science. 2016. Vol. 43. Article number 012037. DOI: https://doi.org/10.1088/1755$1315 / 43 / 1 / 012037$

4. Леонова А. В. Факторы оврагообразования в районе строительства Северской АЭС в Томской области / А. В. Леонова; науч. рук. Т. Я. Емельянова // Проблемы геологии и освоения недр: труды XIII Международного симпозиума имени академика М. А. Усова студентов и молодых ученых, посвященного 110 -летию со дня рождения К. В. Радугина. Томский политех- нический университет (ТПУ), Институт геологии и нефтегазового дела (ИГНД). Томск: Изд-во ТПУ, 2009. С. 206-207.

5. Ольховатенко В. Е., Чернышова Н. А., Краевский А. А. Геоэкологическая оценка и прогноз осадок грунтовых толщ при длительном водопонижении на оползнеопасной территории Лагерного сада г. Томска, Изд-во: ТГАСУ, 2013127 с.

6. Состояние геологической среды (недр) территории Сибирского федерального округа в 2015 г. Информационный бюллетень, выпуск 12, АО «Томскгеомониторинг», Томск: ООО «Д-принт», 2016. 160 с.

7. Ghorbanzadeh O., Feizizadeh B., Blaschke T. An interval matrix method used to optimize the decision matrix in AHP technique for land subsidence susceptibility mapping // Environmental Earth Sciences. 2018. Vol. 77. Article number 584. DOI: https://doi.org/10.1007/s12665-018-7758-y

8. Gudiyangada Nachappa T., Tavakkoli Piralilou S., Ghorbanzadeh O., Shahabi H., Blaschke T. Landslide Susceptibility Mapping for Austria Using Geons and Optimization with the Dempster-Shafer Theory // Applied Sciences. 2019. Vol. 9 (24). Article number 5393. DOI: https://doi.org/10.3390/app9245393

9. Gudiyangada Nachappa T., Kienberger S., Meena S.R., Hölbling D., Blaschke T. Comparison and validation of per-pixel and object-based approaches for landslide susceptibility mapping // Geomatics, Natural Hazards and Risk. 2020. Vol. 11. No. 1. P. 572-600 DOI: https://doi.org/10.1080/19475705.2020.1736190

10. Guzzetti F., Reichenbach P., Ardizzone F., Cardinali M., Galli M. Estimating the quality of landslide susceptibility models // Geomorphology. 2006. Vol. 81. P. 166-184. DOI: 10.1016/j.geomorph.2006.04.007

11. Ivanova E. Landslide Susceptibility Mapping using Frequency Ratio and Analytic Hierarchy Process (AHP): Comparative study of two areas in Bulgaria // Proceedings of the International Conference Analysis and Management of Changing Risk for Natural Hazards, 18-19 November, 2014, Padua, Italy. 2014. pp. AP23-1-AP23-9. URL: https://www.researchgate.net/publication $/ 318589814$

12. Rasyid A.R., Bhandary N.P., Yatabe R. Performance of frequency ratio and logistic regression model in creating GIS based landslides susceptibility map at Lompobattang Mountain, Indonesia // Geoenvironmental Disasters. 2016. vol. 3. Article number 19. DOI: https://doi.org/10.1186/s40677-016-0053-x

13. Zhang Y.X., Lan H.X., Li L.P., Wu Y.M, Chen J.H., Tian N.M. Optimizing the frequency ratio method for landslide susceptibility assessment: A case study of the Caiyuan Basin in the southeast mountainous area of China // Journal of Mountain Science. 2020. Vol. 17. Article number 2. DOI: https://doi.org/10.1007/s11629-019-5702-6

14. Zhuang J., Peng J., Zhu X, Ma P., Liu T. Spatial distribution and susceptibility zoning of geohazards along the Silk Road, XianLanzhou // Environmental Earth Sciences. 2016. Vol. 75. Article number 711. DOI: https://doi.org/10.1007/s12665-016-5428-5 15. Покровский Д. С., Кузеванов К. И. Гидрогеологические проблемы строительного освоения территории Томска // Обской вестник. 1999. № 1-2. С.96-104.

16. Lee S., Thalib J. A. Probabilistic landslide susceptibility and factor effect analysis // Environmental Geology. 2005. Vol. 47. P. 982-990. https://doi.org/10.1007/s00254-005-1228-z

17. Саати Т.Л. Принятие решений. Метод анализа иерархий. М.: Радио и связь, 1989. 316 с.

18. Linden A. Measuring diagnostic and predictive accuracy in disease management: An introduction to receiver operating characteristic (ROC) analysis // Journal of Evaluation in Clinical Practice. 2006. Vol. 12, P.132-139. DOI: $10.1111 /$ j.13652753.2005.00598.x 


\title{
Assessment of landslide processes on the territory of Tomsk by using GIS technologies
}

\author{
(C2021 A.V. Leonova, L.A. Strokova ${ }^{\bowtie}$, A. N. Nikitenkov \\ National Research Tomsk Polytechnic University, \\ 30 Prospekt Lenina, 634050, Tomsk, Russian Federation
}

\begin{abstract}
Introduction: Currently, the city of Tomsk is extending its area of development, new housing blocks are appearing on previously undeveloped land (e.g. on the left bank of the river Tom), the central part of the city is being redeveloped and reconstructed. Without taking into consideration the dynamics, mechanisms, factors, and patterns for the development of dangerous natural and technogenic-natural processes and the forecasting of their development it is not possible to develop the territory qualitatively. The goal of the work is to establish patterns for the occurrence of landslides, to estimate the intensity of their development, and to predict the probability of their occurrence within the new boundaries of the city.

Research methods: The assessment and forecast of landslide development were performed with the help of GIS technologies, which are an important tool for the city's management due to their ability to process and analyse multidimensional data regarding the geological environment. Two methods were used to determine the "weight" of factors contributing to the development of landslides: the analytical hierarchical process (AHP) and the frequency ratio (FR). The analysis of curves for Receiver Operating Characteristics (ROC) was used to validate the susceptibility maps.

Results and discussion: A map of the distribution of landslides within the territory of the city was created. The map includes 25 landslide locations. These landslides were randomly divided into two parts: 17 landslides $(70 \%)$ to train the model and 8 landslide locations $(30 \%)$ to validate the model. Seven factors were selected to analyse spatial patterns that determine the development of landslides: slope angle, slope aspect, curvature, elevation, geological structure of the territory, types of filtration sections, and the distance to the river. A training set of data was used to create susceptibility prediction maps by ranking the factors by two methods. Spatial correlation between the location of landslides and contributing factors was identified using GIS-based statistical models. The quality of the models was evaluated by means of a ROC-curve analysis. The area under the curve was 0.750 for the AHP-model and 0.844 for the FR-model, which shows the high quality of the prediction maps. Thus, both methods have proved useful in assessing the susceptibility of areas to landslides.

Conclusions: Landslide susceptibility maps for the territory within the new boundaries of the city were created for the first time and the quality of the models was checked. The maps are recommended to be used to monitor and manage swiftly the geological environment, to evaluate land in the urban area, and to teach the discipline "Engineering Geodynamics".
\end{abstract}

Keywords: landslide, susceptibility, mapping, frequency ratio; analytical hierarchical process, ROC curve analysis

For citation: Leonova A. V., Strokova L. A., Nikitenkov A. N. Assessment of landslide processes on the territory of Tomsk by using GIS technologies. Vestnik Voronezhskogo gosudarstvennogo universiteta. Seriya: Geologiya - Proceedings of Voronezh State University. Series: Geology. 2021, no.1, pp. 94-103. DOI: https://doi.org/10.17308/geology.2021.1/3341

Conflict of interests: The authors declare the absence of obvious and potential conflicts of interest related to the publication of this article.

Ludmila A. Strokova, e-mail: sla@tpu.ru 


\section{REFERENCES}

1. Olkhovatenko V. E., Rutman M. G., Lazarev V. M. Opasnye prirodnye i tehnoprirodnye processy na territorii g. Tomska $i$ ih vlijanie na ustojchivost' prirodno-tehnicheskih sistem [Dangerous natural and technological processes on the territory of Tomsk and their impact on the stability of natural and technical systems]. Tomsk, Pechatnaja manufaktura publ., 2005, 152 p. (In Russ.) 2. Olkhovatenko V.E., Lazarev V.M., Filimonova I.S. Geojekologicheskie problemy zastrojki territorii Tomsk i meroprijatija po of the territory of Tomsk and measures for its engineering protection]. Vestnik Tomskogo gosudarstvennogo arhitekturno-stroitel'nogo universiteta $=$ Bulletin of the Tomsk state University of architecture and construction, 2012, no. 1, pp. 141-150. (In Russ.)

3. Leonova A. V., Lomakina K. M., Dmitrieva S. A., Baranova A. V. Geotechnical properties of gullying in Tomsk oblast. IOP Conference Series: Earth and Environmental Science, 2016, vol. 43. Article number 012037. DOI: doi:10.1088/1755$1315 / 43 / 1 / 012037$

4. Leonova A. V. Faktory ovragoobrazovanija v rajone stroitel'stva Severskoj AJeS v Tomskoj oblasti [Factors of gulley formation in the area of construction of the Seversk NPP in the Tomsk region]. A. V. Leonova; scientific adviser T. Ja. Emel'janova. Problemy geologii $i$ osvoenija nedr: trudy XIII Mezhdunarodnogo simpoziuma imeni akademika M. A. Usova studentov i molodyh uchenyh, posvjashhennogo 110-letiju so dnja rozhdenija K. V. Radugina [Problems of Geology and development of mineral resources: Proceedings of the XIII international Symposium named after academician M. A. Usov students and young scientists], Tomsk Polytechnic University. Tomsk, TPU Publishing house, 2009. pp. 206-207. (In Russ.)

5. Olkhovatenko V. E., Chernyshova N. A., Kraevskij A. A. Geojekologicheskaja ocenka i prognoz osadok gruntovyh tolshh pri dlitel'nom vodoponizhenii na opolzneopasnoj territorii Lagernij Sad Tomsk [Geoecological assessment and forecast of soil sediments during long-term water supply in the landslideprone territory of the Lagerny Garden of Tomsk], TGASU publ., 2013, 127 p. (In Russ.)

6. Sostojanie geologicheskoj sredy (nedr) territorii Sibirskogo federal'nogo okruga $v 2015$ [State of the geological environment (subsurface) of the territory of the Siberian Federal District in 2015]. Newsletter, vol. 12, AO «Tomskgeomonitoring», Tomsk, OOO «D-print» publ., 2016, 160 p. (In Russ.)

7. Ghorbanzadeh O., Feizizadeh B., Blaschke T. An interval matrix method used to optimize the decision matrix in AHP technique for land subsidence susceptibility mapping. Environmental Earth Sciences, 2018, vol. 77, Article number 584. DOI: https://doi.org/10.1007/s12665-018-7758-y

8. Gudiyangada Nachappa T., Tavakkoli Piralilou S., Ghorbanzadeh O., Shahabi H., Blaschke T. Landslide Susceptibility Mapee inzhenernoj zashhite [Geoecological problems of development

ping for Austria Using Geons and Optimization with the Dempster-Shafer Theory. Applied Sciences, 2019, vol. 9 (24). Article number 5393. DOI: https://doi.org/10.3390/app9245393

9. Gudiyangada Nachappa T., Kienberger S., Meena S.R., Hölbling D., Blaschke T. Comparison and validation of per-pixel and object-based approaches for landslide susceptibility mapping. Geomatics, Natural Hazards and Risk. 2020, vol, 11, no. 1, pp. 572-600 https://doi.org/10.1080/19475705.2020.1736190

10. Guzzetti F., Reichenbach P., Ardizzone F., Cardinali M., Galli M. Estimating the quality of landslide susceptibility models. Geomorphology, 2006, vol. 81, pp. 166-184. DOI: doi:10.1016/j.geomorph.2006.04.007

11. Ivanova E. Landslide Susceptibility Mapping using Frequency Ratio and Analytic Hierarchy Process (AHP): Comparative study of two areas in Bulgaria. Proceedings of the International Conference Analysis and Management of Changing Risk for Natural Hazards, 18-19 November, 2014, Padua, Italy. 2014. pp. AP23-1-AP23-9, URL: https://www.researchgate.net/publication/318589814

12. Rasyid A. R., Bhandary N. P., Yatabe R. Performance of frequency ratio and logistic regression model in creating GIS based landslides susceptibility map at Lompobattang Mountain, Indonesia. Geoenvironmental Disasters, 2016, vol. 3, Article number 19. DOI: https://doi.org/10.1186/s40677-016-0053-x

13. Zhang Y. X., Lan H. X., Li L. P., Wu Y., Chen J., Tian N. Optimizing the frequency ratio method for landslide susceptibility assessment: A case study of the Caiyuan Basin in the southeast mountainous area of China. Journal of Mountain Science, 2020, vol. 17. Article number 2. DOI: https://doi.org/10.1007/s11629. 019-5702-6

14. Zhuang J., Peng J., Zhu X., Li W., Ma P., Liu T. Spatial distribution and susceptibility zoning of geohazards along the Silk Road, Xian-Lanzhou. Environmental Earth Sciences, 2016, vol. 75. Article number 711. DOI: https://doi.org/10.1007/s12665016-5428-5

15. Pokrovsky D. S., Kuzevanov K. I. Gidrogeologicheskie problemy stroitel'nogo osvoenija territorii Tomska [Hydrogeological problems of construction development of the territory of Tomsk]. Obskoy vestnik - Obskoy Bulletin, 1999, vol. 1-2, pp.96-104. (In Russ.)

16. Lee S., Thalib J. A. Probabilistic landslide susceptibility and factor effect analysis. Environmental Geology, 2005, vol. 47, pp. 982-990. DOI: https://doi.org/10.1007/s00254-005-1228-z

17. Saaty T. L. The Analytic Hierarchy Process: Planning, Priority Setting, Resource Allocation, Mcgraw-Hill, New York, NY. 1980.

18. Linden A. Measuring diagnostic and predictive accuracy in disease management: An introduction to receiver operating characteristic (ROC) analysis. Journal of Evaluation in Clinical Practice. 2006, vol. 12, pp.132-139. DOI: https://doi.org/10.1111/j.1365-2753.2005.00598.x

Авторы прочитали и одобрили окончательный вариант рукописи.

Леонова Анна Владимировна - старший преподаватель отделения геологии Инженерной школы природных ресурсов Национальный исследовательский Томский политехнический университет, Томск, РФ; E-mail: avleonova@tpu.ru;

ORCID: https://orcid.org/0000-0003-2006-571X

Строкова Людмила Александровна - д. г.-м. Н., профессор отделения геологии Инженерной школы природных ресурсов Национального исследовательского Томского политехнического университета, Российская Федерация; E-mail: sla@tpu.ru; ORCID: http://orcid.org/0000-0001-9302-0630

Никитенков Алексей Николаевич - к. г.-м. н., доцент отделения геологии Инженерной школы природных ресурсов Национального исследовательского Томского политехнического университета, Российская Федерация; E-mail: nik@tpu.ru ORCID: http://orcid.org/0000-0002-8539-1420
Anna V. Leonova - senior lecturer, National Research Tomsk Polytechnic University, Tomsk, Russian Federation; E-mail: avleonova@tpu.ru; ORCID: https://orcid.org/0000-0003-2006-571X

Lyudmila A. Strokova - PhD, Dr. habil. in Geol.-Min., professor, Department of Geology, National Research Tomsk Polytechnic University, Russian Federation; E-mail: sla@tpu.ru; ORCID: http://orcid.org/0000-0001-9302-0630

Aleksey N. Nikitenkov - PhD in Geol.-Min., Associate Professor, National Research Tomsk Polytechnic University, Tomsk, Russian Federation; E-mail: nik@tpu.ru

ORCID: http://orcid.org/0000-0002-8539-1420

All authors have read and approved the final manuscript. 